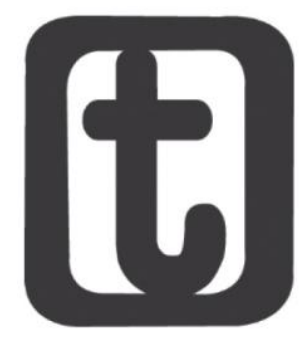

\title{
PENSAMENTO SOCIAL BRASILEIRO E FORMAÇÃO PROFISSIONAL EM SERVIÇO SOCIAL
}

\author{
Brazilian social thinking and professional social service training \\ Evelyne Medeiros Pereira \\ https://orcid.org/0000-0003-2644-0285 \\ Sthefanny Thays Santos Guimarães** \\ https://orcid.org/0000-0001-7202-0092 \\ Danielle Oliveira Cardoso Santos ${ }^{* * *}$ \\ https://orcid.org/0000-0002-0665-852X
}

\begin{abstract}
RESUMO
O presente artigo tem como objetivo analisar como o tema relativo à Formação Social Brasileira (FSB) é tratado na formação profissional de assistentes sociais mediante a utilização de importantes referências do pensamento social crítico brasileiro. A metodologia empregada baseou-se na pesquisa bibliográfica e no estudo das Diretrizes Curriculares para os Cursos de Serviço Social e das ementas dos Grupos Temáticos de Pesquisa (GTPs) da Associação Brasileira de Ensino e Pesquisa em Serviço Social (ABEPSS). Como desdobramento desse processo, é possível revelar que, mesmo diante das lacunas encontradas no diálogo com a FSB, há uma importância incontroversa dos conhecimentos sobre a realidade brasileira para a formação profissional em Serviço Social, ganhando centralidade em face ao atual contexto histórico.
\end{abstract}

\section{PALAVRAS-CHAVE}

Formação Social Brasileira. Formação Profissional. Serviço Social.

\section{ABSTRACT}

This article aims to analyze how the theme related to the Brazilian Social Formation (BSF) is treated in the professional training of social workers through the use of important references of Brazilian critical social thinking. The methodology used was based on bibliographic research and the study of the Curricular Guidelines for Social Work courses and the summary of the thematic research groups of the Brazilian Association of Teaching and Research in Social Work. As an unfolding of this process, it is possible to reveal that, even in the face of the gaps found in the dialogue with BSF, there is an uncontroversial importance of knowledges about the brazilian reality for professional training in social work, gaining centrality in the current historical context.

\footnotetext{
* Assistente Social. Doutora em Serviço Social. Professora Adjunta do Departamento de Serviço Social da Universidade Federal de Pernambuco. (UFPE, Recife, Brasil). Av. Prof. Moraes Rego, 1235, Cidade Universitária, Recife (PE), CEP.: 50670-901. E-mail: evelyne.mp2913@gmail.com.

** Graduanda em Serviço Social pela Universidade Federal de Pernambuco. (UFPE, Recife, Brasil). Av. Prof. Moraes Rego, 1235, Cidade Universitária, Recife (PE), CEP.: 50670-901. E-mail: sthefanny.g@hotmail.com.

*** Graduanda em Serviço Social pela Universidade Federal de Pernambuco. (UFPE, Recife, Brasil). Av. Prof. Moraes Rego, 1235, Cidade Universitária, Recife (PE), CEP.: 50670-901. E-mail: dani.o.c.s@hotmail.com.
}

\section{DOI 10.22422/temporalis.2020v20n40p14-29}

(cc) Br Commons Atribuição 4.0 Internacional (https://creativecommons.org/licenses/by/4.o/deed.pt_BR), que permite copiar e redistribuir o material em qualquer suporte ou formato, bem como adaptar, transformar e criar a partir deste material para qualquer fim, mesmo que comercial. O licenciante não pode revogar estes direitos desde que você respeite os termos da licença.

Temporalis, Brasília (DF), ano 20, n. 40, p. 14-29, jul./dez. 2020. | ISSN 2238-1856 


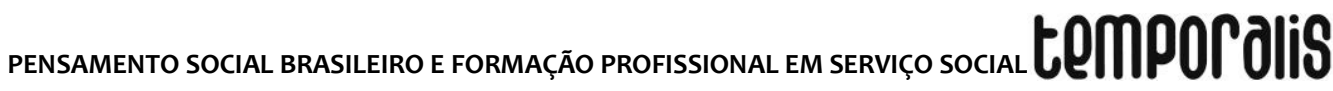

KEYWORDS: Brazilian Social Formation. Professional Training. Social Work.

\section{INTRODUÇÃO}

$\mathrm{O}$

estudo sobre a realidade brasileira tem sido cada vez mais emergente e necessário para o nosso tempo histórico. Considerada a trajetória desta imensa nação interrompida para os de baixo, profundamente desigual e que hoje se apresenta com traços distópicos, agravantes e ameaçadores no contexto da primeira grande pandemia no capitalismo contemporâneo, muitos/as analistas têm recorrido ao legado que nos foi deixado por referências do pensamento social brasileiro. Tais referências, através de formas, perspectivas e meios distintos, certamente têm muito a nos dizer sobre o que nos particulariza, enquanto formação social, na universalidade do modo de produção capitalista.

Contudo, é preciso destacar que a herança deixada pelos/as “intérpretes do Brasil” é composta por diferentes campos de interpretação e matrizes metodológicas, filosóficas e ideopolíticas. Nesse caminho, se farão presentes figuras representativas da eugenia racial, a exemplo de Raimundo Nina Rodrigues (1862-1906) e Oliveira Viana (1883-1951); do emergente empresariado, como Roberto Simonsen (1889-1948); e do lusotropicalismo de Gilberto Freyre (1900-1987). Outros também se destacaram nessa trajetória, embora noutras perspectivas, centrando suas análises nos estudos sobre patrimonialismo e cultura política no país, a exemplo de Sérgio Buarque de Holanda (1902-1982) e Raymundo Faoro (1925-2003).

Em polo distinto, um conjunto de autores/as irão se distinguir, apresentando outro fio condutor e perspectiva para pensar o Brasil e as bases da Formação Social Brasileira (FSB) num diálogo aderente à teoria social crítica e às experiências das revoluções populares mundo afora. Esses/as pensadores/as, em sua maioria engajados/as em importantes organizações políticas de trabalhadores/as, tinham por objetivo não apenas conhecer melhor nossa formação social, mas entendê-la para transformá-la. Para isso, a questão em torno da revolução brasileira torna-se um eixo fundamental e condutor para a pensar a FSB.

Daí a busca de situar o Brasil na dinâmica capitalista, considerando as relações sociais internas e externas conectadas a uma forma específica de integração ao mercado mundial que constituiu um desenvolvimento econômico no país profundamente submetido e subjugado aos interesses da grande burguesia internacional. Elementos estes impeditivos de maiores avanços na soberania nacional, o que, para alguns, instituiu uma forma de capitalismo dependente, atravessado pelo peso da conservação frente às necessidades de modernização. Isto, entretanto, só foi possível mediante o esforço no entendimento sobre a natureza das classes sociais e o caráter da revolução burguesa nessas terras. Dentre outras referências, destacamos algumas contribuições centrais, cada uma a seu modo e com os limites do seu tempo histórico: Caio Prado Jr. (1907-1990), Nelson Werneck Sodré (1911-1999), Antônio Candido (1918-2017), Darcy Ribeiro (19221997), Celso Furtado (1920-2004), Florestan Fernandes (1920-1995), Jacob Gorender (19232013), Clóvis Moura (1925-2003), Lélia Gonzalez (1935-1994), Octávio Ianni (1926-2004), 
Francisco de Oliveira (1933-2019), Heleieth Saffioti (1934-2010) e Carlos Nelson Coutinho (1943-2012).

É preciso ressaltar que não estamos tratando de uma perspectiva homogênea. Apesar dos traços comuns, há também aí uma enorme diversidade e inúmeras polêmicas. Algumas, inclusive, em aberto até hoje. Contudo, priorizamos no presente artigo o diálogo com os/as autores/as que mais se aproximam da tradição marxista e que, portanto, nos ajudam a entender essa realidade e seus efeitos fora do circuito de interpretações dualistas rígidas. Isto com objetivo de situar em que medida o pensamento dessas/es intérpretes influenciaram (a ainda influenciam) a formação profissional em Serviço Social no Brasil.

Ressaltamos, ainda, que as formulações e sistematizações que aqui apresentamos são fruto dos trabalhos desenvolvidos junto aos processos de iniciação científica, conjugados à pesquisa docente intitulada Formação Social do Brasil e Serviço Social: a realidade brasileira na formação de assistentes sociais, em andamento desde o último ano. Isto nos permitiu construir uma maior aproximação às principais contribuições teóricometodológicas do pensamento social crítico brasileiro para o entendimento das particularidades do desenvolvimento capitalista no país, especialmente da questão social, além de identificar algumas das sinalizações sobre as principais influências dos/as intérpretes do Brasil na literatura mais referenciada na renovação crítica do Serviço Social brasileiro. Por se tratar de um exercício de síntese no âmbito das pesquisas ainda em andamento, afora os limites certos deste texto, ainda destacamos a importância e relevância do tema em meio ao contexto em que vivemos no Brasil e no mundo e suas repercussões para o Serviço Social, particularmente para a formação profissional.

\section{PENSAMENTO SOCIAL BRASILEIRO E RENOVAÇÃO CRÍTICA DO SERVIÇO SOCIAL}

Mesmo que não seja de nosso conhecimento a existência de uma literatura específica, ou mesmo de uma pesquisa de maior fôlego, que trate sobre a influência do pensamento social brasileiro no Serviço Social, partimos do pressuposto de que tal aproximação tem um importante marco histórico: a renovação crítica do Serviço Social brasileiro na intenção de ruptura com o conservadorismo (NETTO, 1990). Isto considerando que, anteriormente, no período de vigência do Serviço Social Tradicional (YASBEK, 2009), há uma predominância de um arranjo teórico-doutrinário (IAMAMOTO, 2014) marcado pela forte e inconteste influência europeia e, especialmente, norte-americana dos construtos teórico-metodológicos e técnico-operativos sobre os quais a profissão era regida nestes territórios.

Assim, nos parece coerente a afirmação de que é a partir da crítica aos parâmetros do Serviço Social Tradicional que o Serviço Social, como profissão e área de conhecimento (MOTA, 2013), desenvolverá um diálogo com o pensamento social brasileiro, desde as tendências mais desenvolvimentistas, que subsidiaram perspectivas como o desenvolvimento de comunidade, passando pela interpretação enviesada das ideias freirianas na reatualização conservadora, até uma aproximação com as/os autores/as marxistas. E é exatamente sobre este último momento que nos debruçaremos a partir de então, na busca de revelar a contribuição desses/as intérpretes no processo de formação profissional. 


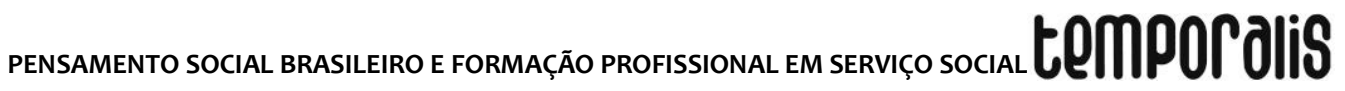

Basta um rápido esforço para observarmos, por exemplo, a presença e a influência das ideias de Carlos Nelson Coutinho, que lecionou na Escola de Serviço Social da Universidade Federal do Rio de Janeiro (UFRJ), e produziu importantes e referenciadas obras - parte delas diretamente relacionada à FSB - que passaram a ser leitura obrigatória nos cursos de Serviço Social em todo o Brasil desde a década de 1980.

As páginas iniciais do livro Ideologia do Desenvolvimento de Comunidade no Brasil, de Safira Bezerra Ammann (1980), prefaciado por Florestan Fernandes, também sinalizam os caminhos desse diálogo. Além disso, duas das mais importantes e imprescindíveis referências, já clássicas no Serviço Social Crítico da América Latina, também apresentam profunda relação com o legado deixado pelos/as pensadores/as da FSB aqui priorizados/as por nós. Referimo-nos à Marilda Vilela lamamoto e José Paulo Netto.

A primeira é reconhecida como pioneira na profissão visto que se dedicou aos estudos marxistas voltados à questão social e às suas particularidades na realidade brasileira, chegando a abordar temáticas como a questão agrária - mais precisamente a análise do processo de constituição da condição operária na agroindústria canavieira. Contribuições estas expressas de forma mais precisa nas obras Trabalho e Indivíduo Social (2001) e Serviço Social em tempo de capital fetiche: capital financeiro, trabalho e questão social (2007), nas quais a autora demonstra sua aproximação com autores importantes da FSB, a exemplo de Octávio Ianni e José de Souza Martins. Contudo, é importante ressaltar que, mesmo não tratando diretamente da relação entre Serviço Social, questão social e FSB, já na obra Relações Sociais e Serviço Social no Brasil: esboço de uma interpretação histórico-metodológica (1982) existe a presença do diálogo com autores como Octavio lanni, responsável pela elaboração da quarta capa do referido livro.

O segundo traz na sua própria trajetória político-acadêmica a presença irremediável [frente à natureza de seu objeto de pesquisa] da referência marxiana e marxista, temperada pelas ideias de Florestan Fernandes e do orientador de sua tese, Octavio Ianni. Daí surge, em 1990, a publicação intitulada Ditadura e Serviço Social: uma análise do Serviço Social no Brasil pós-64, valorosa contribuição para os fundamentos da profissão, sendo hoje um dos livros mais lidos nos cursos de graduação de Serviço Social no país, que, inclusive, representa um importante salto no esforço presente e explícito de entrelaçar os fundamentos da profissão aos fundamentos da vida social, particularizados através dos elementos constitutivos da FSB.

Na década seguinte, outra publicação passa a se destacar como uma importante contribuição e referência na formação de assistentes sociais, mais precisamente, no debate sobre neoliberalismo, Estado brasileiro e políticas sociais. Trata-se do livro Brasil em contra-reforma: desestruturação do Estado e perda de direitos, de Elaine Rossetti Behring (2003) que, ao priorizar o diálogo com a FSB a partir, por exemplo, da concepção de heteronomia contida no pensamento de Florestan Fernandes, dentre outros/as autores/as, reforça a atualidade desse legado e das ideias daqueles/as que nos deixaram contribuições imprescindíveis para pensar a formação do capitalismo brasileiro, ontem e hoje.

Outras tantas expressões mais recentes dessa influência e diálogo poderiam ser aqui listadas e indicadas, tal como os livros Questão Social e Serviço Social no Brasil:

Temporalis, Brasília (DF), ano 20, n. 40, p. 14-29, jul./dez. 2020. | ISSN 2238-1856 


\section{tempordilis}

fundamentos sócio-históricos, de Ivone Maria Ferreira da Silva (2008), e Questão Social: particularidades no Brasil, de Josiane Soares Santos (2012), da Biblioteca Básica de Serviço Social. Contudo, mereceriam uma pesquisa mais aprofundada.

A questão que gostaríamos de chamar atenção é que, mesmo diante dessas evidências, o caminho ainda parece muito longo frente às necessidades postas não apenas ao conjunto de assistentes sociais, mas a classe trabalhadora como um todo. Necessidades estas crescentes no tempo presente. Não à toa, algumas iniciativas despontaram no último ano, a exemplo das coletâneas Formação Social e Serviço Social: a realidade brasileira em debate e Desenvolvimento, Formação Social Brasileira e Políticas Públicas: subsídios analíticos para o Serviço Social, ambas de 2019, além de uma série de dissertações e teses que vem pondo como centro nas análises a FSB. Isto revela, por um lado, a atualidade do legado do pensamento social crítico no âmbito da FSB para o estudo e o enfrentamento das expressões contemporâneas da questão social na particularidade brasileira; por outro lado, a necessidade viva e pulsante dos desafios postos ao Serviço Social, já sinalizados por lamamoto (2014), tais como o de "[...] impulsionar estudos históricos sobre a formação sócio-histórica do Brasil e a América Latina, favorecendo estudos comparados" (IAMAMOTO, 2014, p. 634).

A relação entre a FSB e Serviço Social é crucial, mesmo que com fissuras, para dar concretude, viabilidade, consequência e movimento a um conjunto de mediações demandadas pela dimensão particular da vida social. Eis um dos mais importantes pilares para a instrumentalidade do Serviço Social e de seu Projeto Ético-político Profissional, pois necessita não apenas do arcabouço teórico-metodológico que viabilize revelar os determinantes sócio-históricos da realidade social e da questão social no capitalismo, mas de um conjunto de instrumentos técnico-operativos que permita, sob uma orientação ético-política, articular e mobilizar elementos locais (particulares) e universais para o trabalho no cotidiano profissional.

É, portanto, no seio dessa trajetória que as Diretrizes Curriculares (DCs) para os cursos de graduação em Serviço Social são conformadas e estruturadas, fruto de um conjunto de iniciativas desenvolvidas por parte dos sujeitos coletivos e entidades representativas da profissão sob uma direção social estratégica coadunada com um projeto societário (e profissional) de enfrentamento ao conservadorismo e de profundo diálogo com a perspectiva histórico-crítica e com a tradição marxista (NETTO, 2009). Tais iniciativas são parte do mesmo processo que viabiliza a renovação crítica da profissão cujo os marcos coincidem com aqueles que tornaram possível um salto qualitativo para a formação profissional expresso na proposta de DCs apresentada pela ABEPSS (1996). Isto, mesmo em meio às adversidades que cresciam e ameaçavam ainda mais a educação pública no contexto neoliberal, bem como as demais políticas e serviços sociais.

A referida proposta anuncia e defende uma formação capaz de subsidiar um perfil profissional com “[...] capacitação teórico-metodológica, ético-política e técnicooperativa para a apreensão teórico-critica do processo histórico como totalidade". Isto, "considerando a apreensão das particularidades da constituição e desenvolvimento do capitalismo e do Serviço Social na realidade brasileira" (ABEPSS, 2020, não paginado). E mais: "o trato rigoroso da questão social e de suas particularidades na realidade social" numa perspectiva crítica e dialética (ABEPSS, 2020, não paginado). 


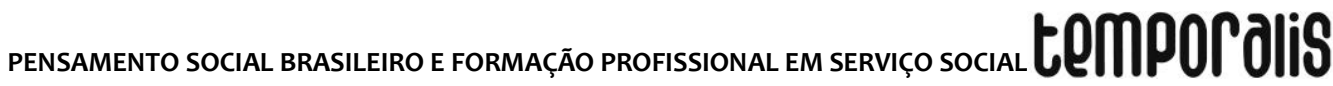

Dentro dessa proposta de formação, com profunda relação e compromisso com os interesses das classes trabalhadoras, que tem como marco o III Congresso Brasileiro de Assistentes Sociais (CBAS) - o Congresso da Virada -, a construção das bases para o currículo mínimo de 1982, o Código de Ética Profissional de 1993, entre outros, que incorrerá junto a isso uma necessidade de repensar a realidade brasileira, seus fundamentos sócio-históricos e conexões com a profissão. Isto terá sua expressão mais tangível com a constituição de três principais núcleos de fundamentos, articulados entre si, que passarão a ser alicerces da nova lógica curricular e representar o conjunto de conhecimentos fundamentais para a formação de assistentes sociais no Brasil, quais sejam: 1. Núcleo de fundamentos teórico-metodológico da vida social; 2. Núcleo de fundamentos da formação sócio-histórica da sociedade brasileira; 3. Núcleo de fundamentos do trabalho profissional. E é exatamente sobre o segundo núcleo que nos debruçaremos, a partir de então, tendo como base as DCs e as orientações construídas pelos GTPs da ABEPSS.

\section{A FORMAÇÃO SOCIAL BRASILEIRA NAS DIRETRIZES CURRICULARES E NOS GTPS DA ABEPSS}

Com o objetivo de identificar como a realidade brasileira - enquanto particularidade da realidade social sobre a qual a categoria de assistentes sociais despende estudos, análises e ações planejadas, no âmbito da formação e do trabalho profissional - compõe a proposta de formação profissional em Serviço Social no território nacional, desde a renovação crítica e sob sua direção, buscamos, a partir de então, pontuar alguns aspectos mais gerais sobre o trato do eixo/núcleo de fundamentos da formação sócio-histórica da sociedade brasileira nos documentos relativos às DCs para os cursos de graduação em Serviço Social (ABEPSS, 1996; BRASIL, 2002). Isto, priorizando as diretrizes da ABEPSS de 1996, tendo em vista que as DCs para os cursos de Serviço Social, publicadas pela Resolução $n^{\circ}$ 15, de 13 de março de 2002, do Ministério da Educação (MEC), apresentam uma série de alterações em relação às da ABEPSS e mesmo em relação às DCs elaboradas pela comissão de especialistas de ensino em Serviço Social, de 1999.

Observemos que o núcleo de fundamentos da formação sócio-histórica da sociedade brasileira "[...] remete ao conhecimento da constituição econômica, social, política e cultural [...]” (ABEPSS, 1996, p. 11) desta formação social, "[...] na sua configuração dependente, urbano industrial, nas diversidades regionais e locais, articulada com a análise da questão agrária e agrícola, como um elemento fundamental da particularidade histórica nacional" (ABEPSS, 1996, p. 11). Isto atentando para os movimentos que conformam a FSB, "[...] suas desigualdades sociais, diferenciação de classe, de gênero e étnico raciais, exclusão social, etc”. (ABEPSS, 1996, p. 11). Identificamos a importância de tal núcleo para compor a formação profissional quando atrelada aos fundamentos teórico-metodológicos da profissão, considerando sua relação com os fundamentos da vida social. Tais fundamentos devem dialogar entre si para que exista uma maior compreensão acerca dos processos que envolvem o desenvolvimento do país, bem como analisar suas tendências e impactos para a FSB e no próprio Serviço Social.

De modo geral, para além do núcleo específico de fundamentos da formação sóciohistórica da sociedade brasileira, percebemos que os elementos mais importantes para tratar das particularidades da realidade brasileira dentro das DCs de 1996 são: Trabalho,

Temporalis, Brasília (DF), ano 20, n. 40, p. 14-29, jul./dez. 2020. | ISSN 2238-1856 
Estado, Classes sociais, Políticas Sociais, Questão Social e Lutas Sociais. Além disso, observamos a ausência dos eixos relativos diretamente à formação cultural da sociedade brasileira.

Evidenciamos, a partir da análise documental, que o ementário que trata sobre a Formação sócio-histórica do Brasil como "matéria básica" [que deve subsidiar o desdobramento de disciplinas, seminários temáticos e demais componentes curriculares] é o único constituído por "períodos históricos", não por conteúdos e eixos centrais como os demais ementários. Assim, alguns aspectos importantes da FSB, presentes no pensamento social crítico, tal como "capitalismo dependente", "desenvolvimento desigual e combinado", "padrão autocrático burguês", "transformações pelo alto", "democracia e autoritarismo", "questão agrária" e "questão racial”, além de não constarem na ementa, parecem se diluir nos conteúdos, merecendo destaque a depender do direcionamento dado pelos diversos sujeitos que passam a coordenar e orientar as graduações nas diferentes regiões do país. Isto mesmo que alguns desses elementos, a exemplo da "herança colonial" e "modernização conservadora", se apresentem de forma mais explícita. Vejamos:

Formação sócio-histórica do Brasil: A herança colonial e a constituição do Estado Nacional. Emergência e Crise da República Velha. Instauração e colapso do Estado Novo. Industrialização, urbanização e surgimento de novos sujeitos políticos. Nacionalismo e desenvolvimentismo e a inserção dependente no sistema capitalista mundial. A modernização conservadora no pós-64 e seu ocaso em fins da década de 70. Transição democrática e neoliberalismo (ABEPSS, 1996, p. 16).

Observamos, portanto, um menor peso dos elementos sociológicos, de fundamentos da FSB e uma maior atenção para a caracterização de períodos, marcos legais e fatos históricos com o intuito de "particularizar" a realidade social, o que tende, a depender da condução de cada colegiado de curso, à uma abordagem formal e presa à cronologia histórica da realidade brasileira e de sua formação social, isolada em componentes curriculares específicos. Diante disso, nos arriscamos a afirmar, a partir desta aproximação inicial, que essa abordagem tende a ser o "trato" predominante no Serviço Social para com o tema da FSB, apesar dos avanços enormes com a renovação crítica, expressos e explicitados nas próprias DCs. Isto incide diretamente nas disciplinas de Fundamentos históricos, teóricos e metodológicos do Serviço Social (FHTMSS, que podem secundarizar a relação entre a FSB, os fundamentos e a trajetória do Serviço Social como profissão. Ainda sobre essa "matéria básica", fica evidente a prioridade dada ao século XX, não contemplando os elementos necessários para aquilo que demanda as próprias DCs da ABEPSS (1996): uma análise que "[...] se direciona para a apreensão dos movimentos que permitiram a consolidação de determinados padrões de desenvolvimento capitalista no país" (ABEPSS, 1996, p. 11). Para tanto, seria de fundamental importância a abordagem e o trato em torno dos aspectos que caracterizaram a transição entre uma sociedade escravocrata, servil e colonial para uma sociedade competitiva e capitalista.

Percebemos em duas outras "matérias básicas", como é o caso de Política Social e Administração e Planejamento em Serviço Social, a ausência, ao menos de forma explícita, do diálogo com a realidade brasileira. No que diz respeito à matéria de Pesquisa social, não há também uma referência direta em sua ementa, por exemplo, da categoria da

Temporalis, Brasília (DF), ano 20, n. 40, p. 14-29, jul./dez. 2020. | ISSN 2238-1856 


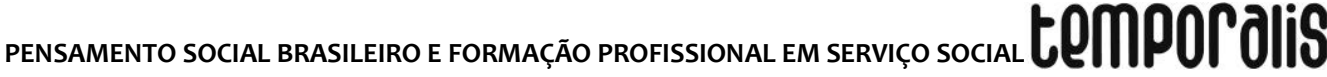

particularidade como mediação importante para a produção de conhecimentos no âmbito do Serviço Social. Isto tendo em vista a notoriedade deste aprendizado e exercício, durante a formação básica das/os assistentes sociais, para o trabalho profissional e a necessidade demandada por este de compreender a realidade em sua totalidade social, particularizando-a, o que é impossível se fazer sem considerar os fundamentos da FSB.

Outro elemento, não menos importante, tem relação com a "matéria básica" de Acumulação Capitalista e Desigualdades Sociais. Esta põe em seu debate a questão da posição do Brasil na divisão internacional do trabalho, dialogando com a constituição das classes sociais no país, do Estado e das particularidades regionais na perspectiva do "[...] desenvolvimento desigual e combinado das estruturas fundiárias e industrial" (ABEPSS, 1996, p. 17). Trata-se, portanto, de uma matéria que apresenta um potencial, do ponto de vista do diálogo com a FSB, para um conjunto de iniciativas que podem e devem ser desenvolvidas no processo de formação profissional que tendem a afinar a articulação entre os seus três núcleos centrais de fundamentação.

Quanto às referências bibliográficas do próprio documento das DCs da ABEPSS, dentre os/as autores/as referenciais no estudo sobre o Brasil em suas produções, identificamos a presença de Marilena Chauí, Carlos Nelson Coutinho, Florestan Fernandes e Darcy Ribeiro.

Ainda observamos que as alterações realizadas e expressas nas DCs do MEC (BRASIL, 2002), em relação àquelas de 1996, da ABEPSS, deixaram menos explícita a perspectiva teórico-metodológica no trato da FSB e, em específico, dos conteúdos relativos ao núcleo de fundamentos da formação sócio-histórica brasileira, como uma necessidade de particularizar a realidade social e que, portanto, deve ser um núcleo fundamentalmente articulado com os demais.

Para o entendimento sobre a materialidade que assumem tais DCs na formação profissional, também priorizamos o diálogo com o ementário dos 8 (oito) GTPs da ABEPSS, considerando a importância que esses grupos vêm adquirindo na formação profissional e na própria ABEPSS, reconhecendo-os como "[...] espaço dinâmico, estimulante e efetivo de elaboração, produção e circulação do conhecimento [...]"(ABEPSS, 2020, não paginado), congregando pesquisadores/as da área de Serviço Social e afins "[...] para tratarem de temas de relevância social [...]"(ABEPSS, 2020, não paginado) e promovendo a "[...] integração entre a pesquisa desenvolvida nas unidades de formação acadêmicas (UFAs) e as linhas de pesquisa consideradas relevantes para a área [...]" (ABEPSS, 2020, não paginado). Diante disso, direcionemo-nos, então, às ementas de cada GTP.

\section{GTP Trabalho, Questão Social e Serviço Social}

Ementa: Trabalho e ser social. Crítica da economia política. Produção e reprodução da vida social. Aspectos econômicos, políticos e culturais e seus desdobramentos no quadro da pobreza e da desigualdade social. Divisão do trabalho no capitalismo mundializado e os fundamentos da lei do desenvolvimento desigual e combinado. Especificidades regionais e as expressões da questão social, reveladoras da condição dependente e subordinada dos países da América Latina. Elementos constitutivos da reestruturação produtiva do capital e suas repercussões no mundo do trabalho. Trabalho e formas de

Temporalis, Brasília (DF), ano 20, n. 40, p. 14-29, jul./dez. 2020. | ISSN 2238-1856 
exploração contemporâneas. Sujeitos sociais, práticas de classe e direitos do trabalho. Cultura do trabalho no século XXI. Políticas sociais e trabalho. Relações de trabalho do assistente social (ABREU, 2018, p. 158, grifos nossos).

Este grupo tem sua ementa direcionada para entender os processos que permeiam o trabalho, destacando aspectos econômicos e sociais. Ressaltamos como elementos centrais para nossa análise a referência dada às "especificidades regionais" e "expressões da questão social" enquanto aspectos fundamentais para entender a "condição de dependência" do capitalismo na América Latina. Desse modo, identificamos que há uma notória preocupação deste GTP por relacionar os temas mais abrangentes relativos aos estudos sobre trabalho e questão social com àqueles que dizem respeito à formação social latino-americana. Entendemos que aí está presente, implicitamente, uma noção de realidade brasileira como parte de uma realidade que é regional. Destacamos também a referência à lei do desenvolvimento desigual e combinado, concepção elaborada inicialmente por Leon Trotsky ([1930] 1977) e desenvolvida por outros/as autores/as marxistas, presente também em larga medida nas obras de Florestan Fernandes ([1975] 2006) que a utiliza, por exemplo, ao tratar das características do desenvolvimento capitalista no Brasil, relacionando-o à dialética entre a dominação imperialista externa e o desenvolvimento desigual interno.

\title{
GTP Política Social e Serviço Social
}

\begin{abstract}
Ementa: Debate conceitual e histórico acerca de categorias teóricas presentes nos fundamentos da política social e sua relação com o Serviço Social. Luta de classes e capitalismo dependente na formação econômico-social brasileira, destacando a formação da classe trabalhadora no Brasil e suas estratégias de resistência. Análise dos processos de formação e institucionalização do sistema de proteção social no Brasil, com ênfase na seguridade social, considerando elementos de comparação na experiência brasileira com outros países, em especial os latino-americanos. As particularidades históricas da formação do Estado no capitalismo dependente e as especificidades na configuração da política social. Impasses da política social no contexto da crise contemporânea do capitalismo, com seus impactos para as classes, o Estado e o fundo público. O contexto de regressão de direitos com a entrada do neoliberalismo no país. Desafios da conjuntura recente, contrarreformas e tendências contemporâneas das políticas sociais no Brasil. Relação entre questão social, política social e Serviço Social (ABREU, 2018, p. 158, grifo nosso).
\end{abstract}

Neste grupo, dentre outros aspectos, destacamos a menção explícita à necessidade de particularizar os conteúdos relativos à política social e Serviço Social, considerando, de forma especial, o tema da condição de dependência do capitalismo na FSB, com destaque para o eixo relativo à formação do Estado brasileiro nesse contexto que, de acordo com Coutinho (2011), se constitui tendo como base um "[...] modo de relacionamento autoritário (mesmo quando paternalista) e antiliberal. É essa dialética de adequação e inadequação que [...] altera-se com a passagem [da subordinação formal] a subordinação real [...]" (COUTINHO, 2011, p. 43) do trabalho ao capital. Eis o solo fértil para edificar uma "[...] 'democracia restrita', aberta e funcional só para os que têm acesso à dominação burguesa" (FERNANDES, [1975] 2006, p. 249), que interdita e tenta a todo custo invalidar o papel mais diretivo das classes subalternas nos processos decisórios do país. Trata-se, portanto, de um GTP com várias sinalizações de diálogos, em potencial, com o pensamento social crítico brasileiro. 


\title{
GTP Fundamentos, formação e trabalho profissional
}

\begin{abstract}
Ementa: O projeto ético-político do Serviço Social como expressão da direção social da profissão e sua interface com os fundamentos, a formação e o trabalho profissional. Fundamentos teóricos do Serviço Social: historicidade, configuração e paradigmas teóricos na realidade nacional e internacional - nos âmbitos latino-americano e mundial. Formação profissional - diretrizes e exigências postas para o ensino, a pesquisa e a extensão no contexto da política de ensino superior brasileira. O trabalho do assistente social nos diferentes espaços sócio-ocupacionais, atribuições e competências e sua respectiva conexão com o mercado de trabalho. Identidade e perfil profissional do Assistente Social na sua relação com as classes sociais e, em particular, com a classe que vive do trabalho (ABREU, 2018, p. 159, grifo nosso).
\end{abstract}

Nesta ementa podemos observar fortemente a presença da historicidade para configurar os "paradigmas teóricos" da profissão na realidade nacional e internacional, apesar de não apresentar, de forma mais direta, os aspectos de encontro entre a FSB e os fundamentos do Serviço Social, bem como a referência teórico-metodológica a ser priorizada para a contextualização da "realidade nacional e internacional". Entendemos que, conforme orientações das DCs da ABEPSS, é fundamental municiar os/as profissionais em formação sobre os aspectos responsáveis pela conformação da profissão na própria historicidade da realidade brasileira. Por vezes, o desenvolvimento histórico da profissão no país é discutido de modo desarticulado em relação à FSB. Assim, apesar do acúmulo que o Serviço Social já dispõe, a dificuldade de explicar historicamente a profissão no Brasil continua a ser um desafio. É preciso dotá-la de mais determinações sócio-históricas que perpassam os aspectos da FSB.

\section{GTP MOVIMENTOS SOCIAIS E SERVIÇO SOCIAL}

Ementa: Classe, consciência de classe e luta sociais; organizações dos trabalhadores: partido e sindicato; o debate dos chamados 'novos movimentos sociais'; as lutas sociais e suas configurações sócio-históricas; a reflexão teóricopolítica e interventiva da relação do Serviço Social com os movimentos e organizações da classe trabalhadora; a intervenção profissional nos processos de mobilização e organização popular; a organização política dos Assistentes Sociais na sua condição de trabalhador assalariado e sua relação com a luta geral dos trabalhadores (ABREU, 2018, p.159, grifo nosso).

A ementa deste GTP destaca a necessidade de contextualizar historicamente o tema das lutas sociais e organização da classe trabalhadora, no entanto, não há especificidades relativas à $\mathrm{FSB}$, bem como referências ao modo como tal formação se constituiu também a partir dos processos de organização e resistência popular, indígena, rural etc. Observamos a ausência de conteúdos relativos às particularidades que constituíram as classes trabalhadoras no Brasil e seus processos de resistência, o que é fundamental para compreensão da própria configuração da questão social, suas expressões e formas de enfrentamento na FSB.

Sobre isso, lembramos das palavras de Clóvis Moura (1988) ao constatar, na ocasião em que se aproximava o centenário da Abolição da escravidão, que pouco se tinha feito de "[...] substantivo para saber-se quais as forças que deram dinâmica à passagem do trabalho escravo para o livre [...]; os componentes objetivos e subjetivos engastados no processo; as forças sociais que atuaram nessa transformação e o nível de contribuição de

Temporalis, Brasília (DF), ano 20, n. 40, p. 14-29, jul./dez. 2020. | ISSN 2238-1856 
cada uma [...]" (MOURA, 1988, p. 16). E ainda acrescenta que a “[...] modernização em cima de uma estrutura social escravista criou condicionamentos no comportamento das classes dominantes brasileiras e de inúmeros dos seus segmentos sociais" (MOURA, 1988, p. 27-28). Como podemos perceber, tal constatação possui uma incomoda atualidade e implica em um processo ainda em aberto no âmbito da pesquisa social como um todo, desafiando o conjunto de pesquisadores/as e profissionais, não apenas no âmbito do Serviço Social, a revelar determinantes sócio-históricos ainda invisíveis, porém não tão menos importantes na realidade brasileira, em especial, quando se trata da temática das classes e lutas sociais.

\title{
GTP QUESTÕES AGRÁRIA, URBANA, AMBIENTAL
}

\begin{abstract}
Objetivo: Aprofundar a construção de fundamentos teórico-metodológicos, em uma perspectiva de totalidade, para embasar a análise crítica das expressões da questão social no âmbito da questão agrária, urbana e ambiental, em sua materialidade na realidade brasileira, bem como sobre as estratégias de intervenção profissional nestes campos (ABREU, 2018, p.159, grifo nosso).
\end{abstract}

Neste grupo temático podemos observar uma diferença em relação aos demais: assemelha-se mais a um objetivo que à uma ementa, de fato. Parece-nos tratar, portanto, de um processo ainda em construção, o que revela o quanto a categoria profissional precisa avançar nos estudos e na apropriação da temática dada a notoriedade da questão agrária, urbana e ambiental na estruturação do capital, desde a sua acumulação primitiva, especialmente na FSB, o que também tem relação com os estudos e pesquisas relativos à gênese e emergência da questão social no Brasil e à própria institucionalização do Serviço Social. Contudo, essas mediações não estão desenvolvidas na ementa, bem como a importância de considerar os aspectos estruturais da transição do capitalismo brasileiro que não demandou, à diferença de outras formações, reformas sociais clássicas, tal como a reforma agrária, conformando, nas palavras de Coutinho (2011, p. 248), "[...] a ideia de que o Brasil transitou para a modernidade capitalista através de uma via não clássica (e não de uma revolução jacobina, desencadeada de baixo para cima)". Ou seja, a constatação de que no Brasil "[...] o empecilho à reprodução capitalista do capital na agricultura não foi removido por uma reforma agrária, mas pelos incentivos fiscais" (MARTINS, 1994, p. 70-80).

\section{GTP RELAÇÕES DE OPRESSÃO/EXPLORAÇÃO DE CLASSE, GÊNERO, RAÇA/ETNIA, SEXUALIDADES}

Ementa: Desdobra-se em três sub-eixos. (a) Gênero: Divisão sexual do trabalho, trabalho doméstico e reprodução social no capitalismo; Condição social das mulheres e políticas públicas. Violência contra mulher e a Lei Maria da Penha: atualidade e desafios. Feminismo: teoria, história, debates e dilemas estratégicos na contemporaneidade. Feminismo e Serviço Social. (b) Raça/Etnia: Estado e raça. Formação social e divisão racial do trabalho no capitalismo. Raça e etnia como construção social. Pensamento Social e raça/etnia. Desigualdades étnicoraciais, de gênero, de geração e classe. Indicadores sócio-demográficos e desigualdade racial. Movimentos sociais e antirracismo. Serviço Social e Políticas públicas de promoção da igualdade racial. Formação profissional e desigualdades étnico-raciais: avanços e desafios para o projeto ético-político do Serviço Social. Exercício profissional, preconceito e discriminação racial. (c) Sexualidades: Diferentes expressões de homofobia e sexismo. Diversidade familiar e opressões associadas às sexualidades não hegemônicas e às múltiplas expressões de

Temporalis, Brasília (DF), ano 20, n. 40, p. 14-29, jul./dez. 2020. | ISSN 2238-1856 


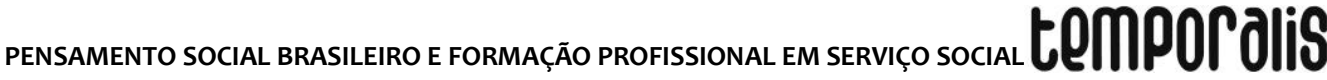

feminilidade e masculinidade. Violações dos direitos sexuais no campo dos direitos humanos. Políticas públicas, gênero, sexualidade e serviço social. Movimentos sociais de enfrentamento à homofobia e ao sexismo (ABREU, 2018, p.160, grifo nosso).

Neste grupo temático, os fundamentos sobre as questões de gênero, raça/etnia e sexualidade buscam se complementar e se articular entre si. No entanto, a ementa não evidencia como a FSB influenciou na articulação dessas dimensões, apresentando um indicativo maior sobre isso ao tratar a questão racial. Em alguns pontos específicos, observamos elementos como "formação social e divisão racial do trabalho", "pensamento social" e "formação profissional", sem especificar ou explicitar o Brasil. Entretanto, a própria proposta do GTP de vincular elementos de raça, classe e gênero demonstra, implicitamente, a articulação com a FSB, reiterando a importância dos estudos que consideram a colonização e escravidão no Brasil como processos importantes para a formação das classes sociais no capitalismo brasileiro. Isto nos remete às contribuições de Saffioti (2004), quando nos diz que não se trata de "[...] somar racismo + gênero + classe social, mas de perceber a realidade compósita e nova que resulta desta fusão. [...] Não se trata de variáveis quantitativas, mensuráveis, mas sim de determinações, de qualidades, que tornam a situação destas mulheres muito mais complexa" (SAFFIOTI, 2004, p. 115).

\section{GTP ÉTICA E DIREITOS HUMANOS}

Ementa: Investigação dos fundamentos ontológicos das objetivações éticomorais do ser social: determinações, natureza, modos de ser e contradições da vida cotidiana e na práxis sócio-histórica. Abordagem sócio-histórica da ética profissional: referências filosóficas, ethos profissional, particularidades, contradições, conflitos e implicações políticas, na formação e no exercício profissional. A ética na pesquisa em Serviço Social: peculiaridades e enfrentamentos. Estudo dos fundamentos sócio-históricos dos Direitos Humanos: sua gênese e configuração na sociedade moderna; seu desenvolvimento na sociedade contemporânea, no interior das lutas sociais entre classes e projetos políticos. Investigação das diferentes manifestações e práticas sociais orientadas por valores ético-políticos emancipatórios e pela defesa dos $\mathrm{DH}$ no interior da sociedade capitalista e do Serviço Social, em face da formação e do exercício profissional, visando identificar os seus limites e as suas possibilidades de realização. Investigação das diferentes formas de opressão e de violação dos direitos humanos, evidenciando os sujeitos e seu processo de resistência: reivindicações, estratégias de luta, conquistas e práticas cotidianas (ABREU, 2018, p.160, grifo nosso).

O grupo temático supracitado aborda o debate em torno da ética e seus fundamentos sócio-históricos e dos Direitos Humanos, a partir da sua gênese e configuração na sociedade, bem como no âmbito da formação e do exercício profissional do/a assistente social. Observamos o debate predominantemente acerca da ética e o Serviço Social, também em termos gerais, pouca proximidade (explicitamente) sobre a particularidade brasileira. Isto diante de uma realidade conformada com base em um padrão autocráticoburguês (FERNANDES, 2006) que inviabilizou a ampliação democrática, o que é fundamental ser considerado no estudo sobre Direitos Humanos. Trata-se, portanto, de uma formação social que se constituiu exatamente pelo mesmo movimento que inviabilizou os direitos humanos através da exploração estrutural que relaciona classe,

Temporalis, Brasília (DF), ano 20, n. 40, p. 14-29, jul./dez. 2020. | ISSN 2238-1856 
raça/etnia e gênero. Não considerar tais aspectos no debate da ética na profissão pode significar uma lacuna considerável na formação profissional.

\section{GTP SERVIÇO SOCIAL, GERAÇÃO E CLASSES SOCIAIS}

Ementa: O debate geracional no mundo contemporâneo. Os processos que envolvem infância, juventude e velhice enquanto construções sociais, históricas e culturais, bem como expressões da questão social. Indicadores socioeconômicos, proteção social e protagonismo político. As demandas pela reconfiguração do espaço urbano e de equipamentos sociais. O trabalho do assistente social junto à infância, juventude e velhice (ABREU, 2018, p. 161, grifo nosso).

Destacamos como elementos importantes na referida ementa a concepção de que os eixos que compõem a temática em questão (infância, juventude e velhice) se constituem como "construções sociais, históricas e culturais" que, nesta condição, acompanham o movimento da realidade, desde a sua dimensão universal à singular. Portanto, tais construções dizem respeito também à um conjunto de aspectos que conformam a FSB, afinal, como entender o processo de envelhecimento sem diferenciar padrões de acumulação e de exploração que são profundamente desiguais? Como estudar a juventude sem considerar a particularidade desse segmento social em formações com maior peso do racismo no Estado e nas suas formas de enfrentamento à questão social? Tais elementos nos parecem servir para um bom debate junto aos diversos sujeitos que pesquisam (e atuam) sobre esta temática, atentando para a importância do pensamento social crítico brasileiro nos estudos geracionais e culturais.

\section{CONSIDERAÇÕES FINAIS}

Sob o amparo teórico de importantes referências do pensamento social brasileiro, é possível revelar a centralidade dos conhecimentos sobre a FSB para o campo de mediações que constitui a dimensão particular da realidade e configura a questão social no Brasil. Isso nos demonstra que o estudo sobre a FSB, suas aproximações (e distanciamentos) com o Serviço Social ganha centralidade em face ao atual contexto da formação profissional em Serviço Social, o que nos leva a realizar alguns apontamentos finais diante do propósito do presente artigo.

Primeiro, o fato de que a relação intrínseca entre renovação crítica do Serviço Social e o marxismo tem desdobramentos para a importância do diálogo entre a FBS e o Serviço Social. Isto devido à necessidade que passa a existir com maior centralidade na categoria profissional, tanto no âmbito da intervenção quanto da investigação, de atentar para a noção de totalidade social e particularidade, bem como para o exercício de historicizar e contextualizar no sentido de compreender dialeticamente o movimento contraditório das relações sociais. Ressaltamos ainda que a construção dessa direção social da profissão está diretamente conectada às manifestações (e formas enfrentamentos) da questão social no Brasil, demandando o diálogo mais afinado com o pensamento social brasileiro.

Segundo a constatação de que há ainda dificuldades consideráveis em particularizar a realidade social, mesmo diante da necessidade explicitada e orientada, tanto nas DCs quanto no ementário dos GTPs, do diálogo com a FSB atravessar toda a formação profissional. Verificamos a predominância nos grupos temáticos em atentar para o 


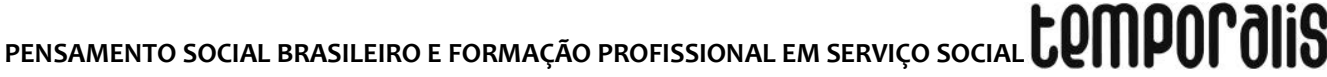

debate em torno dos aspectos da FSB como um dos pilares importantes nas diferentes temáticas, o que ratifica as orientações contidas nas DCs para os cursos de Serviço Social, em especial àquelas referente ao núcleo de fundamentos da formação socio-histórica da sociedade brasileira. No que diz respeito aos elementos explícitos sobre a FSB, de forma geral, o destaque é dado à concepção de dependência nas ementas que tratam do estudo sobre o trabalho, a questão social e a política social. Já naquelas que se remetem mais à relação entre classe, raça/etnia e gênero, há um peso maior dos estudos relativos à questão racial na realidade brasileira. Contudo, é notória também a ausência de tais aspectos em parte dos GTPs, bem como identificado nos componentes curriculares as DCs, sinalizando a atualidade do desafio de impulsionar estudos e pesquisas sobre a FSB e a particularidade regional latino-americana sob uma referência teórico-metodológica coadunada com o Projeto Ético-político Profissional.

Em menor medida, mas não menos relevante, a pesquisa dos documentos orientadores da formação profissional nos levou a identificar também a presença de aspectos que são importantes no pensamento social crítico brasileiro e que influenciaram um conjunto de autores/as, tais como a concepção de desenvolvimento desigual e combinado, presente nas obras de Florestan Fernandes e Carlos Nelson Coutinho, por exemplo. Foi possível também compreender o esforço expresso nos documentos em relacionar as expressões da questão social ao contexto econômico, social e cultural em que elas se apresentam para a profissão. Observamos uma maior preocupação em abordar a particularidade do capitalismo brasileiro no debate sobre política social, trabalho, questão social, fundamentos e formação profissional, questão racial e questão agrária. Apesar do esforço, entendemos que se trata de um processo ainda em construção. Nos eixos temáticos sobre ética, movimentos sociais e geração, por exemplo, tanto nas DCs quanto no GTP, observamos poucas conexões com a particularidade brasileira.

Portanto, tendo o Serviço Social direção coletiva e projeto profissional que não se esgotam nos marcos jurídico-legais, um conjunto de orientações ético-políticas, teóricometodológicas e técnico-operativas que afirme o processo, ainda em curso, de renovação crítica são exigências permanentes e imperativas do tempo presente. Isto especialmente no contexto em que as ameaças conservadoras tomam uma dinâmica inédita, ostensiva e agravada pelas demandas atuais do capitalismo em crise, recompondo traços da FSB, a exemplo da configuração autocrática do Estado, parte do processo de fascistização que impregna socialmente as estruturas de poder no seio da sociedade brasileira (FERNANDES, [1981] 2015). Esse quadro demonstra o quanto, hoje mais ainda, é inegável e indispensável, não apenas ao Serviço Social, o conhecimento crítico da realidade brasileira e sua forma particular de integração ao desenvolvimento capitalista mundial.

\section{REFERÊNCIAS}

ABEPSS. Grupos Temáticos de Pesquisa (GTPs). Brasília (DF), 2020. Disponível em: http://www.abepss.org.br/gtps.html. Acesso em: 6 abr. 2020.

ABEPSS. Diretrizes gerais para o Curso de Serviço Social (com base no currículo mínimo aprovado em Assembleia Geral Extraordinária de 8 de nov. de 1996). Rio de Janeiro, 1996. Disponível em: http://www.abepss.org.br/arquivos/textos/documento_201603311138166377210.pdf. Acesso em: 26 out. 2019.

Temporalis, Brasília (DF), ano 20, n. 40, p. 14-29, jul./dez. 2020. | ISSN 2238-1856 
ABREU, M. M. O Grupo Temático de Pesquisa "Serviço Social: fundamentos, Formação e Trabalho Profissional” no âmbito da ABEPSS - determinações, trajetória e função políticoacadêmico-científica. In: GUERRA, Y. et al (org.). Serviço Social e seus fundamentos: conhecimento e crítica. Campinas: Papel Social: 2018.

AMMANN, S. B. Ideologia do desenvolvimento de comunidade no Brasil. São Paulo: Cortes, 1980.

BEHRING, E. R. Brasil em contra-reforma: desestruturação do Estado e perda de direitos. São Paulo: Cortez, 2003.

BRASIL. Ministério da Educação. Resolução N 15, de 13 de março de 2002. Estabelece Diretrizes Curriculares para os cursos de Serviço Social. Brasília (DF), 2002. Disponível em: http://portal.mec.gov.br/cne/arquivos/pdf/CES152002.pdf. Acesso em: 27 abr. 2020.

COUTINHO, C. N. Cultura e sociedade no Brasil: ensaios sobre ideias e formas. 4. ed. São Paulo: Expressão Popular, 2011.

FERNANDES, F. Poder e contrapoder na América Latina. São Paulo: Cortez, 2015.

FERNANDES, F. A revolução burguesa no Brasil: ensaio de interpretação sociológica. São Paulo: Globo, 2006.

IAMAMOTO, M. V. A formação acadêmico-profissional no Serviço Social brasileiro. Serviço Social e Sociedade, São Paulo, n. 120, p. 609-639, out./dez. 2014. Disponível em: http://www.scielo.br/scielo.php?script=sci_arttext\&pid=S0101-66282014000400002. Acesso em: 27 abr. 2020.

MARTINS, J. de S. O poder do atraso: ensaios de sociologia da História Lenta. São Paulo: Ed. Hucitec, 1994.

MOTA, A. E. Serviço Social brasileiro: profissão e área de conhecimento. Katálysis, Florianópolis: Revista do Programa de Pós-Graduação em Serviço Social, Curso de Serviço Social da Universidade Federal de Santa Catarina, v. 16, n. esp., p. 17-27, 2013. Disponível em: https://www.scielo.br/pdf/rk/v16nspe/03.pdf. Acesso em: 26 dez, 2020.

MOURA, C. Rebeliões da Senzala: quilombos, insurreições, guerrilhas. Porto Alegre: Mercado Aberto, 1988.

NETTO, J. P. Ditadura e Serviço Social: uma análise do Serviço Social no Brasil pós-64. São Paulo: Cortez, 1990.

NETTO, J. P. A construção do projeto ético-político do Serviço Social. In: MOTA, A. E. et al (org.). Serviço Social e Saúde: formação e trabalho profissional. São Paulo: Cortez, 2009.

SAFFIOTI. H. I. B. Gênero, patriarcado, violência. São Paulo: Fundação Perseu Abramo, 2004. (Coleção Brasil Urgente) 


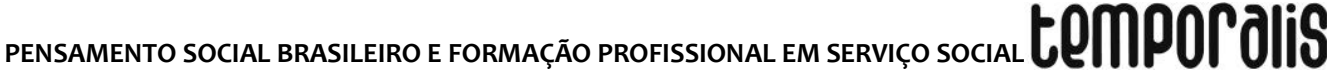

SANTOS, Josiane Soares. Questão Social: particularidades no Brasil. São Paulo: Cortez, 2012. (Biblioteca Básica de Serviço Social).

SILVA, I. M. F. da. Questão Social e Serviço Social no Brasil: fundamentos sócio-históricos. Cuiabá, MT: EdUFMT, 2008

TROTSKY, L. A história da Revolução Russa. 2. ed. Rio de Janeiro: Paz e Terra, 1977. YASBEK, M. C. Os fundamentos históricos e teórico metodológicos do Serviço Social brasileiro na contemporaneidade. In: CFESS. Serviço Social: direitos sociais e competências profissionais. Brasília: CEAD/UnB, 2009.

Evelyne Medeiros Pereira Trabalhou na concepção e delineamento; análise e interpretação dos dados; redação do artigo, revisão crítica e na aprovação da versão a ser publicada.

Assistente Social. Doutora em Serviço Social pela Universidade Federal do Rio de Janeiro (UFRJ). Professora Adjunta do Departamento de Serviço Social da Universidade Federal de Pernambuco (UFPE). Membro da Associação dos Amigos da Escola Nacional Florestan Fernandes (ENFF) e da Coordenação do GTP Serviço Social e Movimentos Sociais da Associação Brasileira de Ensino e Pesquisa em Serviço Social (ABEPSS).

Sthefanny Thays Santos Guimarães Trabalhou na concepção e delineamento; análise e interpretação dos dados e na redação do artigo.

Graduanda em Serviço Social pela Universidade Federal de Pernambuco.

Danielle Oliveira Cardoso Santos Trabalhou na concepção e delineamento; análise e interpretação dos dados e na redação do artigo.

Graduanda em Serviço Social pela Universidade Federal de Pernambuco. 